\title{
Physiological Growth Response in Seedlings of Arabica Coffee Genotypes Under Contrasting Nursery Microenvironments
}

\author{
Taye Kufa ${ }^{1,}$, J. Burkhardt ${ }^{2}$ \\ ${ }^{1}$ Ethiopian Institute of Agricultural Research, Jimma Agricultural Research Center, Jimma, Ethiopia \\ ${ }^{2}$ University of Bonn, Institute of Crop Science and Resource Conservation-Plant Nutrition, Bonn, Germany
}

Email address:

kufataye@yahoo.com (T. Kufa), j.burkhardt@nui-bonn.de (J. Burkhardt)

\section{To cite this article:}

Taye Kufa, J. Burkhardt. Physiological Growth Response in Seedlings of Arabica Coffee Genotypes Under Contrasting Nursery Microenvironments. Plant. Vol. 3, No. 5, 2015, pp. 47-56. doi: 10.11648/j.plant.20150305.11

\begin{abstract}
Arabica coffee genetic resources and shade-grown coffee landscapes are under threat largely due to human activities and lack of scientific information and understanding on adaptation mechanisms along environmental gradients. The study aims to describe the variability in early physiological growth responses in arabica coffee genotypes of varying geographical areas in Ethiopia, its birthplace. The experiment was carried out under contrasting nursery microclimatic settings at the Jimma Agricultural Research Center in Ethiopia. A split- plot design with three replications of two sunlight regimes and twelve-coffee genotypes were arranged as main and sub-plot treatments, respectively. One-year-old coffee seedlings were used to measure shoot and root growth parts and calculate derivatives on physiological parameters. The results depicted that coffee nursery shade gradients had highly significant influence on leaf mass ratio (LMR) with higher value measured in shaded seedlings. In contrast, seedlings under full-sunlight produced significantly higher shoot mass ratio (SMR). Likewise, LMR was highly significantly different due to natural sunlight regimes, genotypes and interaction effects. Seedlings exposed to direct sunlight had relatively higher root mass ratio (RMR), SMR, canopy area (CA) and leaf area index (LAI). The results also revealed significant responses among coffee genotypes in RMR and LMR. Accessions from the drier Harenna areas exhibited the highest RMR, but least LMR. The accession from Bonga had the highest specific leaf area (SLA) and leaf area ratio (LAR) as opposed to the lowest SLA and LAR in the Yayu and Harenna populations, respectively. Unlike RMR, LARMR was linked to LMR and was low for Harenna and high for Berhane-Kontir. The results also exhibited reduced specific stem lengths for Harenna and Yayu, which had the highest and lowest LAI, respectively. The study shows considerable differences between open sun and shaded seedlings as well as among arabica coffee genotypes for most physiological growth characteristics considered. The results clearly demonstrate the need for shade microenvironments for production of high quality coffee seedlings with balanced shoot and root growth. The study also describes significantly different magnitudes and patterns of relationships between growth traits for future work. In view of the impacts of changing climate on coffee plant, the findings deliver evidence on genetic diversity within arabica coffee accessions of varying geographical areas in Ethiopia. However, further investigations, inter alia, on detail coffee evolutionary, anatomy, molecular, ecophysiological and desirable agronomic traits across seasons and locations for understanding adaptation strategies to environmental stresses and identifying suitable coffee cultivars for specific geographical areas.
\end{abstract}

Keywords: Coffee Environments, Genetic Diversity, Microclimate, Physiological Traits, Wild Coffee

\section{Introduction}

The montane rainforest areas in Ethiopia are the only known center of origin and genetic diversity for arabica coffee (Coffea arabica L). In its natural forest area, arabica coffee occurs in the multi-strata of forest ecosystems and thus it is a shade-adapted plant. Its response to light has caused it to be traditionally considered a heliophobic plant requiring high, somewhat dense cover in a plantation. However, the cultivation of modern coffee plantation in open sun is not uncommon in most coffee producing countries, though its sustainability is questionable. It is known that coffee trees with high productivity potential are capable of high yields when they are cultivated intensively without shade $[1,4]$. In 
perennial crops like coffee, basically the ultimate measure of early screening of coffee seedlings is the growth potential that influences the chance of survival of any seedling [2]. Similarly, research findings indicated the possibility of early screening of arabica coffee cultivars under specific nursery management inputs and to predict the later adaptation and mitigation strategies in coffee trees [3].

Arabica coffee shows some remarkable features, which distinguish it from the other coffee species. Spontaneous coffee populations and their progenies have distinct genetic variability. The characteristics controlled by major genes from those under polygenic determinations include, among others, branching habit, young leaf color and measured plant morphological parameters. Nonetheless, such responses depend upon plant species and cultivar and have been used as criteria to characterize coffee cultivars [4]. It is known that photosynthesis in coffee follows the $\mathrm{C}_{3}$ or Calvin cycle pathway, as coffee plants placed in darkness after a period of light produce a burst of $\mathrm{CO}_{2}$ following photorespiration [5].

According to the work done in Kenya [6], about $95 \%$ of the photosynthetic products of a plant are derived from the carbohydrates manufactured in the green parts by the process of photosynthesis and the remaining 5\% come from mineral elements absorbed by the roots. According this report, the capacity of the plant to produce carbohydrate depends mainly on the total green (mainly leaf) area engaged in photosynthesis and the net photosynthetic rate per unit green surface area. The same author depicted that dry matter production in any crop depends upon leaf area index, structure of the canopy, photosynthetic rate per unit of leaf area and strength of the metabolic sinks in attracting assimilates.

The cultivation of coffee plantation in open sun has been successful due to the high adaptability of coffee plants to different irradiance levels [7]. Light provides the energy needed for photosynthesis, and canopy shading from trees may influence plant productivity and seedling survival. Irradiance (quantum flux density) is a key factor in the field, and varies seasonally, diurnally and spatially [8]. The variability in leaf parameters is of broad scientific interest. From an ecophysiological perspective, it may provide clues as to how plants acclimate to their environment and plastic plant structural characteristics. It has been proposed that variability in leaf mass area within the crowns of individual plants optimizes the allocation of leaf carbon with respect to photosynthetic carbon assimilation [9], although it is currently not known whether the variation in leaf-specific area within canopies is adaptive or simply a passive response to an environmental gradient such as light.

As a shade-tolerant species, coffee can be constrained by an inherently low photosynthetic capacity and may suffer from photo inhibition [5]. According to [10], commercial cultivars have retained many of the characteristics adapted to the shady forest environments of the Ethiopian highlands, where Coffea arabica originated. Shade plants essentially follow strategies of optimum use and conservation of available energy, though there is little research information on the phenotypic plasticity and physiological responses of arabica coffee genetic resources under diverse ecological zones. Despite the controversial views between shade- and open field- grown coffee systems and increasing challenges from climate change, there is little information on soil-plantwater relationships in arabica coffee in Ethiopia. Hence, knowledge of physiological adaptation strategies and growth requirements is important for the early evaluation and characterization of coffee germplasm accessions for future works. Moreover, shoot and root growth characteristics are necessary to identify suitable coffee cultivars and to apply effective field management practices. This study was carried out with the aims to describe the physiological growth responses of arabica coffee genotypes and to quantify the relationships between seedling growth characters in shade and full sunlight plots under nursery conditions at Jimma, southwest Ethiopia.

\section{Materials and Methods}

\subsection{Study Area}

The experiment was conducted at a common nursery site of the Jimma Agricultural Research Center, southwest Ethiopia $\left(7^{0} 46^{\prime} \mathrm{N}, 36^{\circ} 0^{\prime} \mathrm{E}, 1750\right.$ m.a.s.l). This is the national coffee research coordinating center where about 6500 live arabica coffee germplasm collections are preserved in field gene banks for research purpose. Though, current climate change and variability has been noticed with its adverse effects, the study site used to receive adequate amount of rainfall with an average rainfall of $1595 \mathrm{~mm}$ per annum distributed into 173 days. The average maximum and minimum air temperatures are 25.9 and $11.2^{\circ} \mathrm{C}$, respectively, the coldest month being December [11].

\subsection{Experimental Procedure and Treatments}

Fully ripe red coffee cherries were collected and prepared from four wild coffee populations in the montane rainforests of southeastern and southwestern Ethiopia. The recommended ideal potting medium [12] was prepared from topsoil and decomposed coffee husk at the respective proportion of $3: 1(\mathrm{v} / \mathrm{v})$ and firmly filled in black plastic pots (volume $=5.8 \mathrm{~L}$ ) perforated at the bottom. The plant plastic pots were arranged on nursery seedbed and the prepared coffee seeds were sown in each pot. The recommended postsowing nursery operations were applied and the seedlings were uniformly managed under moderate shade conditions and well watered at every four-day intervals until starting the treatments.

In this case, seedlings of each coffee accession were divided into equal halves and their physiological growth traits were evaluated in shaded and open sunlight plots. The initial shade cover was removed for the open plot as opposed to overhead (at 2 - $\mathrm{m}$ height) and side shade from bamboo slants. The shade treatment was applied for three consecutive months between March and May, the drier season at the study area. The full sunlight and shaded plots were designed 
to mimic deforested and shade-grown coffee stands, respectively.

\subsection{Experimental Design}

The treatments were arranged in a split-plot design with three replications of shade (open and shaded) and arabica coffee genotypes, which were assigned as a main and subplot factors, respectively. Each treatment consisted of 25 seedlings per plot and the seedlings were arranged on raised beds at a distance of $50-\mathrm{cm}$ spacing. Some microclimate variables were measured throughout the study period and the results depicted significant variations in relative humidity and air temperatures during the day time (Table 1). This can help to examine variability within arabica coffee collections in early growth performance for future investigations.

Table 1. Some microclimate variables in the shaded and full sunlight plots at Jimma coffee nursery site.

\begin{tabular}{llll}
\hline \multirow{2}{*}{ Variable } & \multirow{2}{*}{ RH (\%) } & \multicolumn{2}{c}{ Mean temperature $\left({ }^{\circ} \mathbf{C}\right)$} \\
\cline { 3 - 4 } & $*$ & Air & Soil \\
\hline Time of day & $*$ & $* *$ & Ns \\
Night & $80.97 \pm 9.97 \mathrm{a}$ & $16.56 \pm 1.74 \mathrm{~b}$ & $19.10 \pm 7.16$ \\
Day & $70.82 \pm 6.03 \mathrm{~b}$ & $20.47 \pm 2.01 \mathrm{a}$ & $23.83 \pm 4.23$ \\
Irradiance & Ns & Ns & Ns \\
Sun & $73.42 \pm 8.57$ & $18.75 \pm 3.17$ & $24.03 \pm 5.95$ \\
Shade & $78.36 \pm 9.52$ & $18.28 \pm 2.46$ & $18.90 \pm 5.60$ \\
Mean & 75.89 & 18.51 & 21.46 \\
CV $(\%)$ & 3.17 & 3.58 & 30.42 \\
Time*shade & Ns & Ns & Ns \\
\hline
\end{tabular}

Ns $=$ Not significant; $* \mathrm{P}<0.05 ; * * \mathrm{P}<0.001$. Means were compared according to Tukey test at $\mathrm{P}=0.05$.

\subsection{Data Collection}

One-year-old coffee seedlings were studied and five central seedlings per plot were used for measuring and computing physiological growth parameters. After all the intact data have been recorded; the seedlings were brought to laboratory for destructive measurements on root and aboveground parts. These include dry weight of leaves, main stem, primary branches and root system. Intact leaf area was measured by multiplying average of maximum leaf dimensions (length and width) by a constant $(\mathrm{K}=0.66)$ developed for arabica coffee seedlings [13]. During each harvesting, seedling growth parts were separated into roots, leaves, stems and branches and placed in individual bags. The roots were immersed and washed in clean water to remove adhering soil. The different seedling growth component parts were separately oven dried at $105^{\circ} \mathrm{C}$ for 24 $\mathrm{h}$ and immediately weighed using a sensitive balance.

The relevant derivative physiological growth variables were manipulated as described by others $[14,15]$ : Leaf mass ratio (LMR; leaf mass over total plant mass, $\mathrm{g} \mathrm{g}^{-1}$ ), root mass ratio (RMR; root mass over total plant mass, $\mathrm{g} \mathrm{g}^{-1}$ ), stem mass ratio (SMR; stem + petiole mass/total plant mass, $\mathrm{g} \mathrm{g}^{-1}$ ), specific leaf area (SLA; leaf area/leaf mass, $\mathrm{cm}^{2} \mathrm{~g}^{-1}$ ), leaf area ratio (LAR; leaf area/total plant mass, $\mathrm{cm}^{2} \mathrm{~g}^{-1}$ ), leaf area root mass ratio (LARMR; total leaf area/root mass, $\mathrm{cm}^{2} \mathrm{~g}^{-1}$ ), mean leaf size (MLS; total leaf area/total leaf number, $\mathrm{cm}^{2}$ ), specific stem length (SSL; stem length/(stem + petiole dry mass), $\mathrm{cm} \mathrm{g}^{-1}$ ) and crown area (CA; $\pi \times 0.25 \mathrm{x}$ average crown width $\left.{ }^{2}, \mathrm{~cm}^{2}\right)$ and leaf area index (LAI; total leaf area/crown area, $\left.\mathrm{cm}^{2} \mathrm{~cm}^{-2}\right)$. These variables respectively refer to biomass allocation (RMR, SMR, LMR), leaf display (SLA, LAR), the balance between investment in light intercepting organs against water and nutrient up taking organs (LARMR), the efficiency of biomass investment for height gain (SSL) and crown architecture (CA, LAI) in coffee plant [14].

\subsection{Statistical Analysis}

Data analysis was accomplished using SAS for Windows version 8.1 (SAS Institute Inc., Cary, NC). Two-way analysis of variance (ANOVA) was computed for each seedling growth variable considered in factorial experiment arranged in a Randomized Complete Block design with three replications. Moreover, treatment means were ranked according to Tukey test at $\mathrm{P}=0.05$, whenever the F-test showed significant differences. Figures of significant interactions were made with the SigmaPlot SPW9.0 (SYSTAT Software, Inc.).

The Pearson correlation matrix was run between the most relevant dependent seedling growth variables studied. Moreover, principal component analysis and cluster analysis of the growth parameters were computed to describe the extent of variability among the accessions. Moreover, Canonical Correspondence Analysis ordination technique was carried out using CANOCO for windows version 4.52 [16]. This was undertaken to determine the relationships between different coffee accessions and physiological growth variables considered. In ordination, the angle of the lines with a particular axis is a measure of the degree of correlation (shallow angle means higher correlation). The length of the lines illustrates the significance of the axis in explaining seedling growth variables.

\section{Results}

\subsection{Physiological Growth Responses}

The results depicted that shade management had significant effects on leaf mass ratio $(\mathrm{LMR})(\mathrm{P}<0.001)$ and shoot mass ratio (SMR) $(\mathrm{P}<0.05)$. According, coffee seedlings in moderate and full sunlight plots produced higher LMR and SMR, respectively. This was as opposed to most other architectural growth variables, which showed insignificant variations, neither due to single nor to interaction effects. However, seedlings exposed to direct light had relatively higher root mass ratio (RMR), SMR, canopy area (CA) and leaf area index (LAI) (Table 2).

The results also revealed significant differences among germplasm accessions in RMR $(\mathrm{P}<0.05)$ and LMR $(\mathrm{P}<0.001)$, but not for all the other variables compared. Accordingly, the accession from Harenna showed the highest RMR, but the lowest LMR. Moreover, the accession from Bonga (II-1) had the highest specific leaf area (SLA) and leaf area ratio (LAR) as opposed to the lowest SLA and LAR in 
the Yayu and Harenna accessions, respectively.

Unlike RMR, LARMR was linked to LMR and was low for Harenna and high for Berhane-Kontir. The results also showed significantly reduced specific stem lengths for Harenna and Yayu. Whereas, the smallest and largest crown areas were calculated for Bonga and Yayu seedlings, respectively. As a result, high coefficient of variations was noticed for the crown area as compared to all other variables. But, the Yayu and Harenna accessions exhibited the lowest and highest LAI, respectively (Table 2).

With regard to interactions, the effect between shading and coffee accession was significant $(\mathrm{P}<0.05)$ on $\mathrm{LMR}$ and the respective minimum and maximum average values were obtained from the Harenna and Berhane-Kontir accessions (Table 2). In open sunlight, LMR was reduced in coffee seedlings. Except for three (I-3, III-2 and IV-1), the other accessions (75\%) showed higher LMR in shaded than open plots. This was particularly observed with the Bonga and Berhane-Kontir accessions. However, two accessions (17\%) had almost equal LMR values under low and high light conditions. Moreover, a few accessions (33\%) revealed higher LMR in light-stressed plots. This was especially noted for Bonga. The other coffee accessions, particularly those from Berhane-Kontir and Yayu had increased LMR in shaded conditions (Fig. 1). Growth efficiency of the seedlings did not differ between shade levels, though it decreased with reduced light intensity, averaging $0.010 \pm 0.002 \mathrm{~g} \mathrm{~cm}^{-2}$ and $0.009 \pm 0.002 \mathrm{~g} \mathrm{~cm}^{-2}$ for full-sun and moderate shade, respectively. Average growth efficiency values were slightly higher for the Harenna and Yayu accessions as opposed to Bonga and Berhane-Kontir. As a result, the lowest and highest average results were determined for the Bonga and Harenna accessions, respectively. This was in consistence with SMR, but reciprocal to LMR.

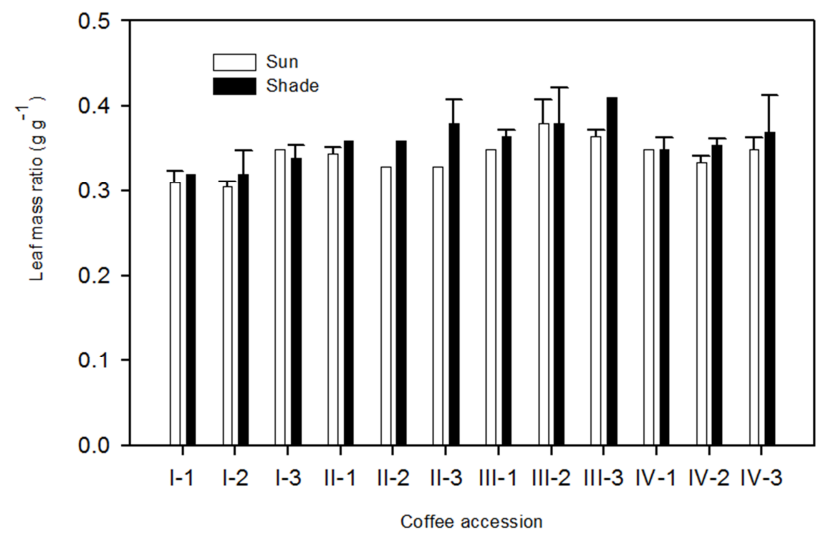

Fig. 1. Leaf mass ratio (LMR) in seedlings of arabica coffee accessions in shaded and full sun plots.

Table 2. Architectural characteristics (means \pm SD) of seedlings based on shade regimes and coffee germplasm accessions.

\begin{tabular}{|c|c|c|c|c|c|c|c|c|c|c|}
\hline Treatment & RMR & LMR & SMR & SLA & LAR & LARMR & SSL & $\mathbf{C A}$ & LAI & GE \\
\hline \multicolumn{11}{|c|}{ Shade regime } \\
\hline Full sun & 0.22 & $0.34 b$ & $0.44 \mathrm{a}$ & 128.80 & 43.89 & 199.88 & 3.80 & 233.06 & 5.01 & 0.010 \\
\hline Shaded & 0.21 & $0.36 \mathrm{a}$ & $0.43 b$ & 131.38 & 47.18 & 225.45 & 4.17 & 208.87 & 4.95 & 0.009 \\
\hline \multicolumn{11}{|c|}{ Accession (Acc) } \\
\hline $\mathrm{I}-1$ & $0.24 \mathrm{ab}$ & $0.32 \mathrm{~d}$ & 0.45 & 133.82 & 41.95 & 179.04 & 3.83 & 259.65 & 5.13 & 0.011 \\
\hline $\mathrm{I}-2$ & $0.25 \mathrm{a}$ & $0.31 \mathrm{~d}$ & 0.44 & 119.10 & 37.35 & 151.52 & 3.77 & 185.48 & 4.48 & 0.012 \\
\hline II-1 & $0.22 \mathrm{abc}$ & $0.35 b c$ & 0.43 & 129.73 & 46.04 & 216.65 & 4.02 & 222.87 & 5.09 & 0.010 \\
\hline II-2 & $0.22 \mathrm{abc}$ & $0.35 \mathrm{c}$ & 0.43 & 155.50 & 53.83 & 243.08 & 4.24 & 201.78 & 5.55 & 0.008 \\
\hline II-3 & $0.23 \mathrm{abc}$ & $0.36 \mathrm{bc}$ & 0.42 & 125.63 & 44.32 & 200.53 & 3.99 & 146.86 & 4.62 & 0.010 \\
\hline III-1 & $0.20 \mathrm{bc}$ & $0.36 \mathrm{bc}$ & 0.45 & 137.27 & 49.19 & 255.08 & 4.01 & 217.22 & 4.71 & 0.009 \\
\hline III-2 & $0.21 \mathrm{abc}$ & $0.38 \mathrm{ab}$ & 0.42 & 120.48 & 45.38 & 223.35 & 4.48 & 165.65 & 4.54 & 0.009 \\
\hline III-3 & $0.18 \mathrm{c}$ & $0.39 \mathrm{a}$ & 0.43 & 123.98 & 47.73 & 261.71 & 3.86 & 229.94 & 5.12 & 0.009 \\
\hline IV-1 & $0.22 \mathrm{abc}$ & $0.35 \mathrm{c}$ & 0.43 & 128.17 & 44.86 & 205.50 & 3.82 & 263.96 & 5.13 & 0.010 \\
\hline IV-3 & $0.22 \mathrm{abc}$ & $0.36 \mathrm{abc}$ & 0.43 & 116.98 & 42.32 & 206.45 & 4.31 & 230.85 & 4.45 & 0.011 \\
\hline Mean & 0.22 & 0.35 & 0.43 & 130.09 & 45.53 & 212.67 & 3.98 & 220.96 & 4.98 & 0.010 \\
\hline CV $(\%)$ & 7.63 & 2.81 & 3.14 & 17.15 & 18.50 & 19.82 & 12.81 & 36.83 & 19.72 & 18.52 \\
\hline \multicolumn{11}{|c|}{ ANOVA $(\operatorname{Pr}>F)$} \\
\hline Shading & Ns & $* * *$ & $*$ & Ns & Ns & Ns & Ns & Ns & Ns & Ns \\
\hline Accession & $*$ & $* * *$ & Ns & Ns & Ns & Ns & Ns & Ns & Ns & Ns \\
\hline Shade*Acc & Ns & $*$ & Ns & $\mathrm{Ns}$ & Ns & Ns & Ns & Ns & Ns & Ns \\
\hline
\end{tabular}

$\mathrm{Ns}=$ Not significant $\mathrm{P}>0.05 ; * \mathrm{P}<0.05 ; * * \mathrm{P}<0.01 ; * * * \mathrm{P}<0.001$. Means with the same letter in a column are not significantly different from each other at $\mathrm{P}<0.05$ (Tukey test). Abbreviations: $\mathrm{RMR}=$ root mass ratio, $\mathrm{LMR}=$ leaf mass ratio, $\mathrm{SMR}=$ stem mass ratio, $\mathrm{SLA}=$ specific leaf area, $\mathrm{LAR}=$ leaf area ratio, $\mathrm{LARMR}=$ leaf area root mass ratio, $\mathrm{SSL}=$ specific stem length, $\mathrm{CA}=$ canopy area, $\mathrm{LAI}=$ leaf area index; GE $=$ growth efficiency.

\subsection{Correlation, Cluster and Principal Component Analyses}

The correlation values (Tables 3a, 3b) depicted that RMR was negatively and significantly $(\mathrm{P}<0.0001)$ associated with
LMW and LARMR in both open sun and shade conditions. Its association with SMR, SLA, LAR and SSL was also indirect, but not significant. In the open sun, RMR was positively related with the other variables, but only significant with TDM $(\mathrm{P}<0.05)$ and $\mathrm{RDW}(\mathrm{P}<0.0001)$. In the 
open sun and shade, the relationship between RMR and SLA was indirect and direct, respectively. In contrast to shaded seedlings, RMR was negatively related to the SDW, CA and LAI of the sun plots with weak associations. This was evident from the positive and significant correlations $(\mathrm{r}=$ 0.92-0.93, $\mathrm{P}<0.001$ ) between SLA and LAR under both light conditions (Tables $3 a, 2 b$ ). The RMR and LMR traits were strongly negatively correlated in open sun $(\mathrm{r}=-0.70 * * *)$ and shaded plots $\left(\mathrm{r}=-0.85^{* * *}\right)$. In open sun, canopy area (CA) was indirectly influenced by all aboveground growth variables, but with significant links between SLA, LAR, LARMR $(\mathrm{P}<0.05)$ and SSL $(\mathrm{P}<0.01)$. In contrast, its relation with LMR was positive and significant $\left(\mathrm{r}=0.41^{*}\right)$. SLA, LAR and LARMR were significantly correlated with LAI in both open sun and shaded treatments. Whereas, root and shoot biomass showed consistent patterns and were significantly and indirectly related to LAR, LARMR and SSL in open sun seedlings. This was where SDW, RDW and TDW showed consistent and significant correlations with morphological and architecture variables. In the shaded seedlings, however, TDM was significantly correlated with LMR $\left(\mathrm{r}=-0.64^{* *}\right)$, LARMR $\left(\mathrm{r}=-0.58^{* *}\right)$ and SSL $(\mathrm{r}=-$ $0.47 *)$, but directly and significantly related to leaf $(\mathrm{P}<0.05)$ and stem $(\mathrm{P}<0.001)$ dry matter accumulations (Tables 3a, 3b).

In addition, at a 15-rescaled cluster distance (85\% similarity), the accessions were grouped into four broad classes with a different number of accessions. Group 1: I-1, I3, II-1, II-2, IV-1, IV-2; group 2: III-1, III-2; group 3: II-3, III-2, IV-3 and group 4: I-2. Consequently, half of the accessions were classified in the same category (group 1), while the extremely distant group had only one accession. Accessions from Bonga, Yayu and Harenna populations were included in the largest groups. Most accessions (17\%) were in a separate class, while the most distant accession was from Harenna (I-2). According to the principal component analysis (Fig. 2), the variables that contributed most to the dissimilarity among the seedlings include LAR, LARMR, LMR, LAI, SLA and RMR. The accessions were comparable in SMR.

Table 3. Correlation values between growth variables of coffee seedlings under full sunlight (a) and shaded (b) microclimatic conditions.

\begin{tabular}{|c|c|c|c|c|c|c|c|c|c|c|c|c|c|}
\hline Variable & RMR & LMR & SMR & SLA & LAR & LARMR & SSL & CA & LAI & LDW & SDW & STW & TDM \\
\hline LMR & $-0.70^{* *}$ & & & & & & & & & & & & \\
\hline SMR & -0.13 & $-0.58 * *$ & & & & & & & & & & & \\
\hline SLA & -0.11 & -0.15 & 0.35 & & & & & & & & & & \\
\hline LAR & -0.38 & 0.26 & 0.09 & $0.92 * *$ & & & & & & & & & \\
\hline LARMR & $-0.70 * *$ & $0.49 *$ & 0.14 & $0.74 * *$ & $0.92 * *$ & & & & & & & & \\
\hline SSL & -0.29 & $0.49^{*}$ & -0.34 & 0.37 & $0.56^{*}$ & $0.54 *$ & & & & & & & \\
\hline $\mathrm{CA}$ & 0.13 & -0.04 & -0.11 & $-0.51 *$ & $-0.49^{*}$ & $-0.43^{*}$ & $-0.59 * *$ & & & & & & \\
\hline LAI & 0.01 & -0.22 & 0.30 & $0.64 * *$ & $0.55^{*}$ & $0.40^{*}$ & -0.17 & 0.32 & & & & & \\
\hline LDW & 0.15 & -0.07 & -0.10 & $-0.51 *$ & $-0.51^{*}$ & $-0.45^{*}$ & $-0.61 * *$ & $1.00 * *$ & 0.33 & & & & \\
\hline SDW & 0.38 & $-0.61 * *$ & $0.42 *$ & -0.30 & $-0.54^{*}$ & $-0.56^{* *}$ & $-0.78 * *$ & $0.78 * *$ & 0.37 & $0.79 * *$ & & & \\
\hline STW & 0.30 & $-0.42 *$ & 0.23 & $-0.40^{*}$ & $-0.55^{*}$ & $-0.55 * *$ & $-0.76 * *$ & $0.91 * *$ & 0.37 & $0.92 * *$ & $0.97 * *$ & & \\
\hline TDM & $0.46^{*}$ & $-0.52 * *$ & 0.19 & -0.40 & $-0.59 * *$ & $-0.64 * *$ & $-0.76 * *$ & $0.87 * *$ & 0.34 & $0.88 * *$ & $0.97 * *$ & $0.99 * *$ & \\
\hline RDW & $0.78 * *$ & $-0.69 * *$ & 0.08 & -0.35 & $-0.61 * *$ & $-0.79 * *$ & $-0.67 * *$ & $0.66^{* *}$ & 0.21 & $0.67 * *$ & $0.85 * *$ & $0.83 * *$ & $0.91 * *$ \\
\hline \multicolumn{14}{|c|}{ b) Shade plot } \\
\hline Variable & RMR & LMR & SMR & SLA & LAR & LARMR & SSL & CA & LAI & LDW & SDW & STW & TDM \\
\hline LMR & $-0.85 * *$ & & & & & & & & & & & & \\
\hline SMR & -0.17 & -0.36 & & & & & & & & & & & \\
\hline SLA & 0.02 & 0.04 & -0.14 & & & & & & & & & & \\
\hline LAR & -0.27 & 0.39 & -0.26 & $0.94 * *$ & & & & & & & & & \\
\hline LARMR & $-0.74 * *$ & $0.73 * *$ & -0.06 & $0.64 * *$ & $0.84 * *$ & & & & & & & & \\
\hline SSL & -0.10 & 0.39 & $-0.51^{*}$ & $0.41 *$ & $0.51 *$ & $0.44 *$ & & & & & & & \\
\hline $\mathrm{CA}$ & -0.33 & $0.41 *$ & -0.18 & -0.14 & 0.01 & 0.18 & 0.17 & & & & & & \\
\hline LAI & -0.08 & 0017 & -0.19 & $0.94 * *$ & $0.92 * *$ & $0.68 * *$ & 0.34 & 0.21 & & & & & \\
\hline LDW & -0.32 & 0.40 & -0.19 & -0.14 & 0.01 & 0.17 & -0.16 & $1.00 * *$ & 0.21 & & & & \\
\hline SDW & $0.42 *$ & $-0.67 * *$ & $0.53 * *$ & -0.21 & $-0.43^{*}$ & $-0.52 *$ & $-0.57 * *$ & 0.31 & -0.08 & 0.32 & & & \\
\hline STW & STW & 0.18 & -0.34 & 0.32 & -0.22 & -0.32 & -0.32 & $-0.51^{*}$ & $0.69 * *$ & 0.03 & $0.69 * *$ & & \\
\hline TDM & $0.56^{* *}$ & $-0.64 * *$ & 0.21 & -0.19 & -0.40 & $-0.58 * *$ & $-0.47^{*}$ & $0.44 *$ & -0.02 & $0.45^{*}$ & $0.94 * *$ & $0.92 * *$ & \\
\hline RDW & $0.92 * * *$ & $-0.87 * *$ & 0.00 & -0.10 & -0.39 & $-0.77 * *$ & -0.30 & -0.02 & -0.09 & -0.001 & $0.72 * *$ & $0.55^{*}$ & $0.84 * *$ \\
\hline
\end{tabular}

$*, * *=$ Correlations are significant at $<0.05$ and $<0.01$ levels, respectively (2- tailed). 


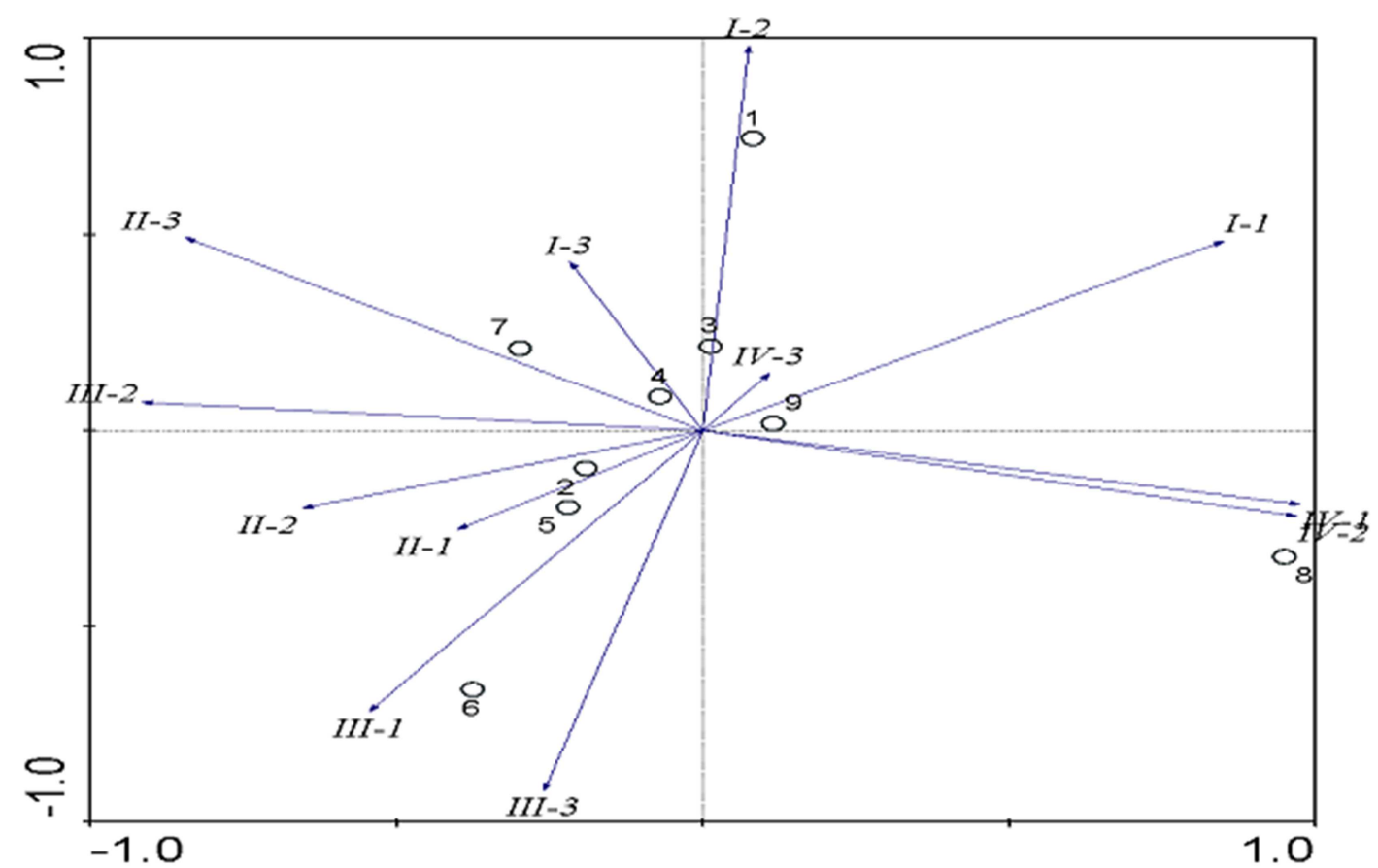

Fig. 2. Principal component analysis biplot of coffee accessions and physiological growth parameters in coffee seedlings (accessions = I-1 to IV-3; parameters $1=R M R, 2=L M R, 3=S M R, 4=S L A, 5=L A R, 6=L A R M R, 7=S S L, 8=C A, 9=L A I)$.

\section{Discussion}

Moderately shaded coffee seedlings had significantly higher LMR, which indicates the higher biomass allocation to the leaves than to the other parts. This is in contrast to most other variables with comparable responses due to single and interaction effects. But, LMR was noted to be more sensitive growth character to compare and screen coffee genotypes under specific environments. Coffee seedlings exposed to direct sunlight had relatively higher RMR, SMR, CA and LAI. The possible explanation for this might be that seedlings in open plots may suffer from heat load and water stress due to more evapo-transpiration. This contrasts with the response of seedlings in shaded plots, where SLA, LAR, LARMR and SSL tended to increase. The results were in line with the biomass production and distribution patterns in coffee seedlings [17]. Shade-grown coffee plants can develop thinner leaves with more thylakoids per granum and more grana per chloroplast, higher chlorophyll content and larger individual leaf area, which allow a more efficient capture of available light energy [16]. Reduced $\mathrm{CO}_{2}$ assimilation rates in coffee leaves subjected to full sun have been associated with leaf temperatures above $25^{\circ} \mathrm{C}$ and with consequent stomatal closure [18].

Coffee seedlings in full sunlight showed considerable reductions in LMR compared to shaded seedlings, demonstrating the increased biomass allocation to leaves than to the other growth parts. This could be related to the three possible reasons [14]. First, very high irradiance levels may lead to irreversible damage to the photosynthetic system. Second, high irradiance around midday leads to stomatal closure and sometimes even to turgor loss and wilting of the leaves [19]. This may have such an impact, even late in the afternoon; light-saturated photosynthetic rates can be considerably lower compared to the morning [20]. Third, high radiation loads require a larger biomass allocation to the roots for water uptake to compensate for transpiration losses.

Moreover, less biomass can be invested in leaf material, which strongly reduces photosynthetic gain and growth potential rate [21]. Seedling growth of tree species at various light levels and it was found that shade-tolerant species showed highest RGR at 16 or $27 \%$, above which it declined, whereas for the pioneer species optima were between 26 and $100 \%$. The results indicated that plant responses to light are governed by different resource constraints at each end of the light gradient. At low light, plants enhance light interception by means of a high biomass allocation to leaves [17] and the formation of thin leaves with a high SLA, leading to a high LAR [22].

Regarding coffee germplasm accessions, seedlings from the Bonga natural forest coffee population had the greatest SLA and LAR as opposed to the lowest SLA and LAR in Yayu and Harenna, respectively. This demonstrated the increased leaf thickness of these accessions as compared to the others and may be related to relative growth and net assimilation rates in coffee seedlings as found for other tropical tree species [14]. This underscores the importance of SLA in explaining difference in accession growth performance in contrasting light situations. As the energy provided by sunlight plays a central role in the metabolism of green plants, plant production is thus limited by the availability of light. The increased SLA and higher carbon storage in low light reflects the adaptive phenotypic plastic plant structural characteristics of coffee seedlings, which enable them to tolerate shade environments, particularly under natural coffee forests. The results were in consistence 
with the extremely variable leaf responses within crowns of arabica coffee trees due to tree and foliage age, location in the crown and direction of exposure to light [13].

In contrast to shaded seedlings, RMR was negatively related to the SDW, CA and LAI of the sun plots. The results may indicate that plant responses to light are governed by different resource constraints at each end of the light gradient. In low light, plants enhance light interception by means of a high biomass allocation to leaves and the formation of thin leaves with a high SLA, leading to a high LAR. A positive correlation between seedling growths in high and low light is also found in a number of other species $[23,24]$. In Ghana, tree species showed a reversal in seedling performance in high irradiance compared to low, whilst pioneer species realized highest growth rates in full sun light, they showed negative growth rates in low light, whereas the shade-tolerant species maintained positive growth rates. It was suggested that realized growth in the field is the result of two components: biomass production through growth and biomass loss as a result of herbivory, mechanical disturbance and shedding [25] and their relative importance differs between habitats. Biomass loss can be minimized by a low leaf turnover and by allowing resources to be stored in the stem and roots. Furthermore, thick, lignified leaves with low SLA at the expense of reduced potential growth can reduce risk of herbivores [26].

The current findings also demonstrated the same responses in SLA and LAI with varying light levels, suggesting the more stable and accession-specific nature of these traits. These traits known to depict resource-use aspects and leaf change was strongly correlated with inherent water-use efficiency, hydraulic conductivity, and grain yield of diverse coffee cultivars [27]. There were differences in the magnitude of association between seedling variables due to shade levels. At high light intensity, plants reduce transpiration losses and increase carbon gain by making small-sized thick leaves with a low SLA. This may be related to the formation of several photo-synthetically active parenchyma layers that can enhance their photosynthetic capacity. Furthermore, such leaves have a thin boundary layer and better heat loss to the environment, and less transpiration is needed for cooling the leaf in a high light environment $[25,28]$. Similar growth patterns have been observed for leaves of seedlings along a light gradient and for leaves of trees along a height gradient in the forest canopy [29]. The increased specific stem length (SSL) for the shaded and accessions from Bonga and Berhane-Kontir may suggest the weak investment in stem and the relative light demands of the seedlings. By contrast, the results showed reduced specific stem lengths for Harenna and Yayu accessions, indicating their superior shoot growth and maximum biomass allocation in stems and petioles as reported earlier $[12,17]$. This is because an increased interception of light through a plastic response in height may lead to only low growth or put the seedling above its whole-light compensation point [30].

A high coefficient of variations $(36.83 \%)$ was obtained for the crown area as compared to all other variables considered.
The Yayu and Harenna accessions had the highest CA and LAI, respectively. This may reflect the variability in seedling size, i.e., morphological growth habits of the compact Yayu and open Harenna coffee types [13]. The plasticity in average leaf size and crown size could also affect the leaf area index and thus photosynthetic capacity and partitioning patterns. The LAI varies with species, cultivars, stage of development, nutrition, availability of moisture and plant population. Below the critical LAI, maximum light interception is not achieved; above the critical LAI, yield may even tend to decline due to shading and competition for water and nutrients. The formation of wide a crown can diminish selfshading, but cannot lead to a lower LAI. The downward flux of PAR is the major factor affecting yield in coffee [31].

Plants shaded by other trees produce larger, thinner and wider leaves, and have higher LAR, LWR and SLA, and lower allocation to the roots [14]. This can result in a decrease in net photosynthesis and stomatal conductance. However, plant responses to light vary with position along the light gradient and those at the lower light gradient enhance their light interception. Several other authors [15, $24,28]$ have shown that shaded plants have a higher biomass allocation to leaves LMR, a higher leaf area per unit leaf mass (SLA), resulting in a higher leaf area per unit plant mass (LAR). There is a reduction in leaf-level light compensation point. Wide crowns with a low leaf area index can reduce mutual shading [30] and such traits would increase net carbon gain at the leaf and whole-plant level by plants growing in the shade, as would mechanisms that enable understory plants to take advantage of brief sun flecks [32].

However, reviews on seedlings grown in artificial environments concluded that biomass distribution patterns of shade-tolerant species showed the opposite trends to those predicted [25]. When grown in low light, small seedlings of shade-tolerant plant species generally had lower LAR than light-demanding associates. The assimilation rate at which arable crops accumulate dry matter during early growth is proportional to the rate at which radiant energy is absorbed by the canopy. The evidence so far suggests that light does not limit yield by net assimilation rate, but that the growth of a crop is almost proportional to the radiation intercepted by its canopy, and the rate of photosynthesis increases with irradiance up to saturating irradiance beyond which it is constant.

The net energy capture hypothesis of adaptation to sun and shade proposes that the consequences of natural selection in shaded habitats should parallel the phenotypic responses shown by seedlings in acclimation to low light [25]. This did not support for the widely held belief that light compensation points in low light are pivotal for shade tolerance differences, as the plasticity of some light-demanding species enables them to maintain lower leaf-level compensation points by greatly increasing SLA in low light [33]. Defense and storage, rather than carbon gain and growth, have therefore been emphasized as key priorities in shaded habitats [23]. The author has indicated that some traits that maximize net 
energy capture, while important for competitive ability in well-lit habitats, might increase the risk of mortality in low light.

As a whole, with increased sunlight LMR, SLA, LAR, LARMR, mean leaf size and SSL decreased, whereas leaf thickness and RMR increased. In this case, water uptake by the plant can be higher due to the increased biomass investment in the roots, resulting in a high RMR and a better balance between transpiring leaf surface and root biomass. Light is the most important determinant of variation in leaf (LMR, SLA, LAR) and water (RMR and LARMR) related growth characteristics of the plant. In contrast, SMR, SLM and LAI seem to be more accession specific [14].

Average growth efficiency values were slightly higher for the Harenna and Yayu accessions as opposed to Bonga and Berhane-Kontir. This is in consistence with SMR, but reciprocal to $\mathrm{LMR}$. LMR was more sensitive to compare coffee accessions along light gradients. In full sunlit, LMR was reduced in coffee seedlings. Most coffee genotypes had higher LMR in the shade than in open sun plots, particularly for the Bonga and Berhane-Kontir accessions, indicating the interaction effect of genetic and environment. Again, few coffee accessions had almost equal LMR values under low and high light conditions, suggesting their broader tolerance to varying light regimes with regard to this trait. This was similar to other growth characters in coffee seedlings [17]. Likewise, growth efficiency, stem wood carbon production per unit leaf area per year [34] was comparable and did not depict significant variations between shade levels and among coffee seedlings. This could be associated to size-related compensation mechanisms and potential changes to increase the water transport capacity of the seedlings to the relative total leaf area [35] increased sapwood area [36] increased driving force between soil and leaf [37] and increased root surface [38, 39]. Hence, growth efficiency is a useful measure, as it standardizes stem wood growth to the amount of leaf area held by each tree and thus, allows comparisons of different sizes with different leaf areas [34, 36]. A large leaf area appears to be of prime importance, as it was not so much attained by biomass allocation to leaves as by the formation of thin leaves with a high SLA. On the other hand, low foliage allocation in high light is clearly an adaptive mechanism in such habitat. This is similar to that of the large and small seedling sizes in groups 1 and 4, respectively. The Bonga and Berhane-Kontir seedlings showed the farthest similarity, partly indicating the magnitude of variations in environmental and coffee plant factors for future breeding works.

The relationships between physiological growth characters in the full-sunlight and shade conditions were related to the extension growth attributes in coffee seedlings. This suggests the tight associations among growth parameters such as morphology, allocation and architecture of coffee seedlings as elaborated [11]. It supports the fact that the direct and diffuse solar radiation output properties of the light are the two main driving variable inputs into the canopy microclimate and photosynthetic assimilations. They largely determine the energy available to the plant canopy for photosynthesis and are vital for driving plant evapotranspiration, soil evaporation and heat fluxes. The findings support others $[40,41]$ who reported reduced LMR and LAR with plant size. Further, the declined SSL in full-sunlight may be associated with the inhibited stem elongation and enhanced total dry matter partitioned to stems. Such seedlings were found to have thicker stems, which may facilitate hydraulic conductance and photosynthesis. This agrees with the report that sun species had a higher proportion of leaf resistance in the xylem [42].

\section{Conclusions}

The study indicates the existence of considerable variations in physiological growth responses between shade levels and among arabica coffee population under controlled conditions. The accessions were grouped into four broad classes of varying number; suggest the need to select the most distant groups in future breeding programs. The correlation results also showed that the various growth characters associated differently with varying magnitudes in open and shaded conditions and thus suggest the strong interactions between coffee genotypes and environmental factors The findings clearly demonstrated the contribution of shade management for production of high quality coffee seedlings and evidenced for the adaptive mechanisms of shade-evolved arabica coffee species. In view of increasing modern coffee plantations in open fields and associated impacts of climate change, urgent collaborative measures should be sought to develop drought tolerant coffee cultivars and promote shade-grown coffee systems for global benefits. Nonetheless, further evaluations are required under more stress field conditions across locations and seasons by considering desirable agronomic traits, including high yield performance, resistance to diseases and insect pests and top quality standards. Moreover, scientific information and knowledge, among others, on diversity in ecophysiological behaviors, molecular characteristics and biochemical constituents among and within arabica genetic resources in Ethiopia await future investigations.

\section{References}

[1] R. M. Chaves, A. Ten-Caten, H. A. Pinheiro, A. Ribeiro, F. M. Damatta, "Seasonal changes in photoprotective mechanisms of leaves from shaded and unshaded field-grown coffee (Coffea arabica L.) trees.” Trees vol. 22, pp. 351-361, 2008.

[2] D. J. Walyero, H. A. M. Van der Vossen, "Early determination of yield potential in Arabica coffee by applying index selection. "Euphytica vol. 28, pp. 465-472, 1979.

[3] Yacob Edjamo, "Relative performance of three CBD cultivars under varying light regimes." Proceedings of the 15th International Scientific Colloquium on Coffee (ASIC), Montpelier, France, 1993. 
[4] J. N. Wintgens, Coffee: Growing, Processing, Sustainable Production. A guide for growers, traders, and researchers. WILEY-VCH Verlag GmbH and Co. KGaA, Weinheim, Germany, 2004.

[5] G. Wrigley, Coffee. Tropical Agriculture Series, London, John Wiley and Sons, Inc., New York, 1988.

[6] M. G. R. Cannell, "Production and distribution of dry matter in trees of Coffea arabica L. in Kenya as affected by seasonal climatic differences and the presence of fruits." Ann.appl. Biol.vol. 67, pp. 99-120, 1971.

[7] J. I. Fahl, M. L. C. Carelli, J. Vega, A. C. Magalhães, "Nitrogen and irradiance levels affecting net photosynthesis and growth of young coffee plants (Coffea arabica L.)." Journal of Horticultural Science vol. 69, pp.161-169, 1994.

[8] F. B. Salisbury, C. Ross, Plant physiology. Wadsworth Publishing Company, Belmont, California 94002, a division of Wadsworth, Inc. 1992.

[9] V. P. G. Gutschick, FW. Weigel, "Optimizing the canopy photosynthetic rate by patterns of investments in specific leaf mass.” Am Nat. vol. 132, pp. 68-85, 1988.

[10] M. K. V. Carr, "The water relations and irrigation requirements of coffee." Experimental Agriculture vol. 37, pp. $1-36,2001$.

[11] Taye Kufa, "Ecophysiological diversity of wild Arabica populations in Ethiopia: Growth, water relations and hydraulic characteristics along a climatic gradient." Ph.D. thesis, Ecology and Development Series, NO 46, Cuvillier Verlag, Gottingen, 305 pp, 2006.

[12] Taye K., Mesfin Abebe, Paulos Dubale, "Dry matter production and distribution in Arabica coffee seedlings as affected by media components." In: Asfaw Z, Getachew B, Belay S, Bulcha W, Nigussie A. (eds.) Proceedings of the Tenth Crop Science Society of Ethiopia (CSSE), SEBIL vol. 10, pp. 154-164, 2004.

[13] Yacob Edjamo, Taye Kufa, Alemseged Yilma, "Varietal and age impacts on Arabica coffee leaf growth parameters at three locations.” In: Kidane Georgis and Yohannes Degago (eds.). Crop Management Options to Sustain Food Security: Proceedings of the 3rd Conference of Agronomy and Crop Physiology Society of Ethiopia (ACPSE), 29-30, May 1997, Addis Ababa, Ethiopia, pp. 38-51, 1998.

[14] L. Poorter, "Growth responses of 15 rainforest tree species to a light gradient: the relative importance of morphological and physiological traits." Func. Ecol. Vol. 13, pp. 396-410, 1999.

[15] H. L. Christopher, "Leaf area accumulation helps juvenile evergreen trees tolerate shade in a temperate rainforest." Oecologia vol. 132, pp. 188-196, 2002.

[16] C. J. F Ter Braak, P. Smilauer, "Canoco for windows version 4.52. Biometrics-quantitative methods in the field and earth sciences". Plant Research International, Wageningen University and Research Center, The Netherlands, 2003.

[17] C. J. F. Ter Braak, P. Smilauer, "Canoco for windows version 4.52. Biometrics-quantitative methods in the field and earth sciences

[18] Taye Kufa, "Biomass production and distribution in seedlings of Coffea arabica genotypes under contrasting nursery environments in southwestern Ethiopia." Agricultural Sciences vol. 6, pp. 835-843, 2012.

[19] D. Kumar, L. L. Tieszen, "Photosynthesis in Coffea arabicaI. Effects of light and temperature." Expl. Agric.vol. 16, pp. 13$19,1980$.

[20] N. R Chiariello, C.B. Field, H.A. Mooney, "Midday wilting in a tropical pioneer tree.” Func Ecol. vol. 1, pp. 3-11, 1987.

[21] L. Poorter, S. F. Oberbauer, "Photosynthetic induction responses of two rainforest tree species in relation to light environment." Oecologia vol. 96, pp. 193-199, 1993.

[22] C. H. Körner, "Some often overlooked plant characteristics as determinants of plant growth: a reconsideration." Func Ecol. vol. 5, pp. 162-173, 1994.

[23] E. M. Veenendaal, M. D. Swaine, V. K. Agyeman, D. Blay, I. K. Abebrese, C. E. Mullins, "Differences in plant and soil water relations in and around a forest gap in West Africa during the dry season may influence seedling establishment and survival. " Journal of Ecology vol. 84, pp. 83-90, 1996.

[24] K. Kitajima, "Relative importance of photosynthetic traits and allocation patterns as correlates of seedling shade tolerance of 13 tropical trees." Oecologia vol. 98, pp. 419-428, 1994.

[25] O. O. Osunkoya, J. Ash, M. S. Hopkins, A. W. Graham, "Influence of seed size and seedling ecological attributes on shade tolerance of rain forest tree species in Northern Queensland." Journal of Ecology vol. 82, pp. 149-63, 1994.

[26] T. J. Givnish, "Adaptation to sun and shade: a whole-plant perspective.” Aust J Plant Physiol. Vol. 15, pp. 63-92, 1988.

[27] D. A. King, "Influence of light level on the growth and morphology of saplings in a Panamanian forest." American Journal of Botany vol. 81, pp. 948-957, 1994.

[28] F. C. Meinzer, J. L. Ingamells, C. Crisosto, " Carbon isotope discrimination correlates with bean yield of diverse coffee seedlings populations " Hort. Science vol. 26, pp. 1413-1414, 1991.

[29] W. Larcher, Physiological Plant Ecology: Ecophysiology and Stress Physiology of Functional Groups (4th ed.). SpringerVerlag, Berlin Heidelberg, Germany, 2003.

[30] H. Poorter, E. Garnier, "Plant growth analysis: an evaluation of experimental design and computational methods." Journal of Experimental Botany vol. 47, pp. 1342-53, 1996.

[31] T. Kohyama, "A functional model describing sapling growth under a tropical forest canopy”. Func Ecol. vol.5, pp. 83-90, 1991.

[32] M. P. H. Gathaara, F. M. Muthur, R. C. Cheruiyot, "Biomass accumulation in the various plant organs of coffee Arabica L., cultivar Ruiru 11, under drip irrigation in Kenya," ASIC 17th Colloquium, Nairobi, pp. 752-759, 1997.

[33] R. L. Chazdon, "Sun flecks in the forest understory." Advances in Ecological Research 18: 1- 63, 1988.

[34] M. B. Walters, P. B. Reich, "Trade-offs in low light $\mathrm{CO}_{2}$ exchange: a component of variation in shade tolerance among cold temperate tree seedlings." Func Ecol. vol. 14, pp. 155$165,2000$.

[35] R. H. Waring, W. G. Thies, D. Muscato, " Stem growth per unit leaf area: a measure of tree vigor. "For. Sci. Vol. 26, pp. 112-117, 1980. 
[36] P. Becker, F. C. Meinzer, S. D. Wullschleger, "Hydraulic limitation of tree height: a critique". Functional Ecology vol. 14, pp. 4-11, 2000.

[37] N. G. McDowell, N. Phililips, C. Lunch, B. J. Bond, M. G. Ryan, "An investigation of hydraulic limitation and compensation in large, old Douglas-fir trees." Tree Physiology vol. 22, pp. 763-774, 2002.

[38] U. G. Hacke, J. S. Sperry, J. Pittermann, "Drought experience and cavitation resistance in six shrubs from the Great Basin, Utah.” Basic and Applied Ecology vol. 1, pp.31-41, 2000.

[39] H. Maherali, E. H. DeLucia, "Influence of climate-driven shifts in biomass allocation on water transport and storage in ponderosa pine." Oecologia vol. 4, pp. 481-491, 2001.
[40] J. S. Sperr, F. R. Adler, G. S. Campbell, J. P. Comstock, "Limitation of plant water use by rhizosphere and xylem conductance: results from a model." Plant, Cell and Environment vol. 25, pp. 347-359, 1998.

[41] U. Niinemets, "The controversy over traits conferring shadetolerance in trees: ontogenetic changes revisited." Journal of Ecology vol. 2, pp. 464-470, 2006.

[42] L. Poorter, "Light-dependent changes in biomass allocation and their importance for growth of rain forest tree species." Func Ecol. vol. 1, pp. 113-123, 2001.

[43] I. Sack, M. T. Tyree, N. M. Holbrook, "Leaf hydraulic architecture correlates with regeneration irradiance in tropical rainforest trees." New Physiologist vol. 2, pp. 403-413, 2005. 